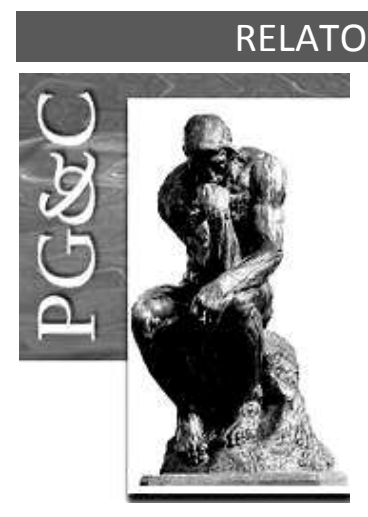

\title{
CONTRIBUIÇÕES DE EDUCAÇÃO A DISTÂNCIA NA APRENDIZAGEM DAS ORGANIZAÇÕES: UM ESTUDO NA UNIVERSIDADE FEDERAL DA PARAÍBA ${ }^{1}$
}

\author{
Débora Gomes de Araújo \\ Mestre em Gestão nas Organizações Aprendentes pela Universidade \\ Federal da Paraíba, Brasil. \\ E-mail: debora.g.de.araujo@gmail.com
}

Guilherme Ataíde Dias

Doutor em Ciências da Comunicação/Informação pela Universidade de São Paulo, Brasil. Professor da Universidade Federal da Paraíba, Brasil.

E-mail: guilhermeataide@ccsa.ufpb.br

\begin{abstract}
Resumo
O conhecimento possibilita a inovação das organizações. Diante desta realidade é fundamental desenvolver ações educativas que favoreçam a aprendizagem dos colaboradores. Neste contexto, o objetivo desta pesquisa é analisar de que forma os cursos na modalidade a distância contribuem com a aprendizagem na organização, a partir da percepção dos servidores técnico-administrativos da Universidade Federal da Paraíba (UFPB). Utilizou-se uma combinação das abordagens quanti-qualitativa. Quanto aos meios, a pesquisa foi de campo, classificada quanto aos fins como exploratória e descritiva, o instrumento para coleta de dados ocorreu por meio de um questionário, em que as perguntas foram baseadas no nível aprendizagem, pertencente ao modelo de avaliação de treinamento de Kirkpatrick, para analisar os dados foi empregado o teste de normalidade Shapiro-wilk e a análise de conteúdo com a técnica de categorização. No que se refere aos resultados, ficou evidente que existe normalidade na distribuição dos dados e que a partir de tais cursos os servidores mencionados expandiram os seus conhecimentos, apresentaram uma evolução das suas habilidades e atitudes, porém sugeriram melhorias no processo com relação a interação, divulgação, infraestrutura do ambiente de trabalho, liderança e cultura organizacional. Concluímos que os cursos EaD contribuem com a aprendizagem organizacional da UFPB e que é necessário uma efetiva gestão do conhecimento para que este venha ser bem aproveitado. Espera-se que o estudo contribua com o fortalecimento dos cursos EaD no âmbito da referida instituição.
\end{abstract}

Palavras-chave: Educação a distância. Aprendizagem organizacional. Tecnologias da informação e comunicação.

\section{CONTRIBUTIONS OF DISTANCE EDUCATION IN ORGANIZATIONAL LEARNING: A STUDY AT THE FEDERAL UNIVERSITY OF PARAÍBA}

\begin{abstract}
Knowledge enables organizations to innovate. Facing this reality is essential to develop educational actions that contribute to the employees' learning process. In this context, the objective of this research is to analyze how the courses in the distance education modality contribute to the organizational learning from the perspective of the Federal University of Paraiba (UFPB) technical-administrative staff. A combination of quantitative and qualitative approaches was used. It was a field research, exploratory and descriptive. The instrument for data collection was a questionnaire. The questions were based on the

\footnotetext{
Artigo desenvolvido a partir de resultados obtidos da dissertação intitulada "Contribuições de educação corporativa na modalidade a distância: um estudo na Universidade Federal da Paraíba", defendida no âmbito do Programa de Pós-graduação em Gestão nas Organizações Aprendentes da Universidade Federal da Paraíba (UFPB).
}

Perspectivas em Gestão \& Conhecimento, João Pessoa, v. 8, n. 1, p. 191-209, jan./abr. 2018. DOI: http://dx.doi.org/10.21714/2236-417X2018v8n1p191.

http://periodicos.ufpb.br/ojs2/index.php/pgc. ISSN: 2236-417X. Publicação sob Licença (cc) EY-Nc-ND 
learning levels associated to Kirkpatrick's evaluation model of training. To analyze the data it was applied the Shapiro-wilk normality test. The content analysis was performed with the aid of a categorization technique. In regard to the research results, it was clear the normality of the data distribution. From the perspective of the courses attended, the employees expanded their knowledge and presented an evolution of their skills and attitudes, but it was suggested improvements in the process with respect to interaction, disclosure, work environment infrastructure, leadership, and organizational culture. We conclude that the distance education courses contribute to UFPB's organizational learning and that an effective knowledge management is necessary for a good use of the organizational learning. We expect this study to contribute with the strengthening of the distance education courses in the UFPB context.

Keywords: Distance education. Organizational learning. Information and communication technologies.

\section{INTRODUÇÃO}

No momento atual, o conhecimento configura-se como um diferencial competitivo para as organizações, quanto mais utilizado mais expressivo constitui-se o valor por ele agregado. Sendo um aspecto fundamental para proporcionar inovação dos produtos e serviços. Neste cenário, as pessoas ocupam um papel essencial, por isso a gestão do capital humano deve ser considerada uma ação primordial para as instituições.

Eboli (2014) discute acerca da era do conhecimento, ao mostrar que o alicerce gerador da riqueza das nações será composto por sua organização social e pelo seu conhecimento gerador, ao estabelecer os indivíduos como protagonistas nesse processo.

$\mathrm{Na}$ segunda metade do século XX, a temática da Gestão do Conhecimento (GC) floresceu, objetivando contribuir com o desempenho das organizações. Ao longo do tempo vem sendo explorada no meio corporativo ao proporcionar competitividade. Segundo Cherman (2012) a GC é primordial para o processo de tomada de decisões, contribuindo para que o saber esteja disponível no momento necessário.

Diante dessa realidade, a organização que identifica suas lacunas de aprendizagem e empreende medidas educativas que cooperam no processo de geração de conhecimentos, não está apenas sobrevivendo, mas ocupando um lugar diferenciado no âmbito corporativo, por isso a necessidade de qualificação contínua dos seus colaboradores.

A partir de um novo paradigma educacional na modalidade à distância, as tecnologias da informação e da comunicação (TIC) contribuem para a disseminação do saber. De acordo com lanni (2001) a onda modernizante se expande encurtando as distâncias e favorecendo as interações sociais. Neste contexto, as pessoas adquirem conhecimentos em seu próprio ritmo, em um processo de conexão com outros, trazendo impacto nas formas de aprendizagem.

Na visão de Schikman (2010) o grau de exigência tem aumentado daqueles que utilizam o serviço público em relação à satisfação de suas demandas. Para o funcionamento adequado de qualquer órgão ou entidade relacionada à administração pública, é necessário a qualificação dos servidores, para que possam desempenhar o trabalho com qualidade, ao prestarem serviços que atendam as demandas dos cidadãos de forma satisfatória. Sendo a educação corporativa uma temática presente também no setor público, pois é fundamental para o desenvolvimento do capital humano, se tratando de uma estratégia gerencial.

Neste contexto, a Universidade Federal da Paraíba - UFPB, ao buscar prestar um serviço de qualidade para o seu cliente-cidadão, tem se esforçado para capacitar os técnico administrativos do seu quadro de servidores, ao ofertar cursos na modalidade a distância, de forma a suprir as necessidades informacionais dos dias atuais e contribuir para um melhor desempenho no exercício das atividades.

Diante destas considerações iniciais, o objetivo desta pesquisa é analisar de que forma os cursos na modalidade a distância contribuem com a aprendizagem na organização, a partir

Perspectivas em Gestão \& Conhecimento, João Pessoa, v. 8, n. 1, p. 191-209, jan./abr. 2018. 
da percepção dos servidores técnico-administrativos da UFPB, tendo como objetivos específicos: verificar a partir da visão destes colaboradores a utilidade dos cursos EaD, na realização dos seus trabalhos e identificar as barreiras que podem prejudicar o emprego eficiente do que foi aprendido a partir dos cursos na modalidade a distância, na percepção dos entrevistados.

O presente artigo está organizado em cinco seções, a partir desta que é a introdução. A seção seguinte refere-se ao referencial teórico, que trata de assuntos inerentes a aprendizagem organizacional $\mathrm{e}$ as tecnologias da aprendizagem. Os procedimentos metodológicos são apresentados na terceira seção, a análise e discussões de resultados na quarta e na quinta têm as considerações finais.

\section{APRENDIZAGEM NAS ORGANIZAÇÕES}

No que concerne à visão estratégica, Ribeiro (2012) enfatiza que cabe a área de recursos humanos proporcionar ações para o desenvolvimento de talentos em um ambiente de trabalho favorável a novas ideias, enxergando as pessoas como parceiras. Rachel e Salomão (2011) coadunam com esta visão dizendo que um ambiente laboral adequado é consequentemente vantajoso para a organização, possibilita a satisfação dos que a ela pertence. Os autores acrescentam que é fundamental o incentivo de oportunidade de crescimento profissional, a empresa passa a adotar um papel estimulador na qualificação dos seus colaboradores, cooperando com resultados satisfatórios.

Ferreira (2017) ao tratar a missão da gestão de pessoas como o alcance da satisfação e motivação dos funcionários revela que a identificação e análise constante do clima organizacional são fundamentais, uma vez que, os colaboradores quando estão mais satisfeitos e motivados com o seu ambiente de trabalho, consequentemente aumentam a produtividade.

Coelho Jr. e Borges-Andrade (2008) mostram que investir no desenvolvimento de ações de aprendizagem eficazes na organização, de maneira tática e sintonizada com os seus objetivos, contribui de forma significativa com o desempenho organizacional e destacam que um cenário apropriado e a motivação do próprio indivíduo que está aprendendo constituem aspectos essenciais para o sucesso ou fracasso de uma ação de aprendizagem.

O capital intelectual da empresa para ser potencializado, requer a gestão de pessoas e do conhecimento, com as ações voltadas a uma aprendizagem contínua (MÓSCA, 2012).

Diante da perspectiva evidenciada pelos autores supramencionados, é evidente que o aprendizado das pessoas nas organizações é algo que não pode ser negligenciado, para isso é necessário ações que capacitem e desenvolvam os colaboradores continuamente, de forma a contribuir com bons resultados.

Senge (2016) explica que pelo fato de ser algo inerente ao ser humano aprender, uma vez que, os indivíduos têm sede e anseiam por isso, as organizações aprendentes são possíveis. Ferreira (2012) ao tratar de uma organização aprendente, atribui a capacidade dos que fazem parte dela têm de aprender ao reverberar para a prática novas competências.

O processo de aprendizagem atua no desenvolvimento de competências demandadas, sendo algo fundamental para que as pessoas e as equipes expressem padrões inovadores de desempenho em um ambiente mais dinamizado e complexo, necessário para a realização de mudanças (NEIVA; RAMOS, 2013).

Para Ferreira (2012) a competência remete ao somatório de conhecimentos, habilidades e atitudes fundamentais para atingir uma determinada finalidade. Behar et al. (2013) complementam dizendo que esse conjunto de elementos é estruturado para enfrentar uma situação nova.

Perspectivas em Gestão \& Conhecimento, João Pessoa, v. 8, n. 1, p. 191-209, jan./abr. 2018. 
Os autores Brandão e Borges-Andrade (2007) dizem existir evidências práticas, que dentre outros fatores, o suporte disponibilizado aos colaboradores pelos colegas cooperam com a transferência de aprendizagem, ou seja, a manifestação de competências no trabalho.

É evidente diante do posicionamento dos autores, a necessidade de investir na aprendizagem dos indivíduos nas organizações, uma vez que, essa ação possibilita inovar continuamente, acompanhando o ritmo do mercado.

Alavi e Leidner (2001) ao pontuarem a respeito da GC dizem que os ativos do conhecimento geram competitividade sustentável para as empresas, uma vez que, não são fáceis de serem copiados e são sociavelmente complexos, necessitando ser manipulados, armazenados e distribuídos para a geração de novos saberes, ou seja, que sejam aplicados eficazmente. Neste contexto, as empresas tem se preocupado em desenvolver, manter, compartilhar, aplicar e transformar o conhecimento constantemente e de modo adequado, necessitando ser absorvido e multiplicado (CHERMAN, 2012).

Diante deste cenário, a educação corporativa (EC) ocupa um lugar de destaque ao promover aprendizagem para os trabalhadores. Neste sentido, Eboli (2014) compreende a EC como um sistema que desenvolve as pessoas, voltado a educação de todos os colaboradores de uma organização. Vieira e Francisco (2012) complementam que o desafio da EC é criar uma cultura inovadora, em que a educação é um processo ligado a toda forma de trabalho, contemplando todos os níveis da organização. O que mostra que a ela estão atreladas as situações de trabalho.

O autor Heemann (2013) apresenta a Educação a Distância (EaD) Corporativa como uma alternativa que possibilita interligar a aprendizagem com as necessidades estratégicas de negócios, ao direcionar o ensino as exigências das organizações de forma objetiva, possibilitando a (re)educação dos colaboradores, reciclando os seus conhecimentos, mediante uma cultura de aprendizagem contínua com o foco no desenvolvimento pessoal e profissional. No mesmo pensamento, Silva et al. (2010) evidenciam que a Educação Corporativa a Distância $(E C a D)$ trata-se de uma solução emergente nas atividades de qualificação dos colaboradores, os quais ao se referirem a EaD tratam da importância da mensuração dos resultados oriundos da aplicação de tal ferramenta, em que nesse processo de avaliação, retratam a necessidade do levantamento de critérios e a definição de indicadores relevantes.

Segundo Rodriguez (2005), as organizações necessitam ser capazes de medir o impacto que tem o investimento de tempo e dinheiro que são direcionados na formação dos seus colaboradores, para tanto apresenta o modelo de Kirkpatrick como um caminho relevante para atingir com sucesso os objetivos de medição.

Diante da visão dos autores é fundamental que seja feito o acompanhamento dos resultados provenientes da aprendizagem na organização. Segundo Palmeira (2012), a avaliação dos programas de educação corporativa e a explicação do que eles causam podem contribuir com a inovação de programas e o aperfeiçoamento dos que já existem, favorecendo o desenvolvimento organizacional, assim como a identificação das competências que a equipe necessita.

Silva et al. (2010) ao tratarem do modelo de avaliação de programas de treinamentos proposto por Kirkpatrick, revela que ele foi um dos precursores nesse processo e enfatizam que o método faz uso de quatro níveis de avaliação, os quais são: reação, aprendizagem, comportamentos e resultados.

Segundo Kirkpatrick e Kirkpatrick (2010a), o nível reação mensura como os participantes dos programas de treinamentos reagiram a eles, revelando assim, a satisfação. Quando a reação não é positiva possivelmente a motivação para aprender é comprometida, prejudicando o aprendizado. No nível aprendizagem, os participantes através das suas modificações de atitudes, da evolução dos conhecimentos e do crescimento de suas habilidades, revelam a ocorrência do aprendizado com a mudança de comportamento, fator 
primordial nesse processo. O nível comportamento refere-se a extensão da mudança de comportamento por parte dos participantes, de forma que os conhecimentos, habilidades e atitudes sejam identificados na suas ações cotidianas. O nível resultados evidencia se os objetivos almejados foram atingidos, os quais podem se referir a crescimento da produção, redução de custos, diminuição de acidentes, aumento das vendas, menor rotatividade dos colaboradores, melhoria da qualidade, crescimento da lucratividade e da rentabilidade.

No olhar de Gil (2012) o conhecimento e as habilidades tornam- se obsoletos, por isso a necessidade da geração de novos conhecimentos para agregá-los ao processo produtivo. 0 aprendizado deve então mostrar como influencia a competitividade da empresa por meio do desempenho dos seus colaboradores, do apoio a estratégia da organização e a contribuição com os resultados, tais quais: qualidade, produtividade, inovação dos produtos e retenção de funcionários.

Diante deste contexto, a UFPB tem empreendido ações de aprendizagem para os seus servidores, em que pode ser verificado com a oferta cursos na modalidade a distância. A referida temática será mais detalhada no próximo ponto.

\subsection{Tecnologias da Aprendizagem}

A educação a distância vem suprir as necessidades de aprendizagem dos dias atuais, segundo Machado e Moraes (2015) trata-se de uma modalidade de ensino inerente aos avanços tecnológicos, assim como a necessidade de qualificação das pessoas. Neste contexto, Silva et al. (2010) trazem que a EaD é a democratização da educação e que o seu aspecto principal é a diminuição da conexão física espaço/tempo, tornando possível que o aprendente em seu próprio ritmo e sem hora e lugar determinado possa realizar os cursos. Para incrementar a ideia, os seus aspectos principais são: ausência de contato físico entre estudantes e professores, utilização das tecnologias de comunicação e informação (TIC), uso de diversas mídias e canais de comunicação, possibilidades de contatos presenciais, aumento da contribuição e cooperação e processo educacional padronizado (MESQUITA; PIVA JR; GARA, 2014).

Silva, Melo e Muyder (2015) revelam que atualmente a palavra chave da EaD é a interação, em que as tecnologias de comunicação mais efetivas exercem um papel fundamental. Teixeira e Stefano (2015) complementam dizendo que a EaD oferece uma educação continuada aos trabalhadores, gerando interação e identidade organizacional e que ela não é uma prática recente das organizações públicas e sem fins lucrativos, sendo utilizada pelas grandes corporações visando capacitar de forma ágil e padronizada vários colaboradores.

No contexto da EaD, os autores Oliveira, Cunha e Nakayama (2016) dizem que a interação e a comunicação entre professores e alunos ocorrem através dos Ambientes Virtuais de Aprendizagem (AVA). Kurtz (2012) enfatiza que os fóruns de discussões, os chats e wikis são ferramentas de interação no referido ambiente.

Silva, Melo e Muyder (2015) destacam que a comunicação é primordial não apenas na interação entre professor/tutor/aluno, pois a institucionalização dos AVA requer o envolvimento de todos os processos organizacionais. Abrangendo todas as etapas, embora que distintas, a comunicação tem assim, um papel influenciador.

Os personagens da $\mathrm{EaD}$ (professor, tutor, aluno e gestor) necessitam possuir competências inerentes ao domínio tecnológico para utilizar as tecnologias digitais, o que é algo primordial nesta modalidade educacional (MACHADO; LONGHI; BEHAR, 2013).

Nesta perspectiva, Rossini (2013) diz que é necessário preparar as pessoas e as organizações metodologicamente ao ser implantada uma nova tecnologia, objetivando obter o máximo de ganho estrutural e conceitual das inovações tecnológicas. O mesmo autor destaca

Perspectivas em Gestão \& Conhecimento, João Pessoa, v. 8, n. 1, p. 191-209, jan./abr. 2018. 
que na contemporaneidade, a mudança ocorre de forma veloz, o que requer que as organizações possibilitem novas conquistas, desafios e estímulos que tragam inovação, qualidade, produtividade, conscientizando as pessoas de que é algo necessário.

Albertin e Brauer (2012) revelam que comumente a resistência a mudanças é mais expressiva no setor público, pela estabilidade, o que consequentemente limita o poder de negociação do gestor, Desta forma, é necessário que este tenha a preparação adequada para lidar com essa situação, de forma a contribuir com a efetividade dos projetos organizacionais. Heemann (2013) alerta que a ausência de familiaridade com o aprimoramento tecnológico pode torna-se algo crítico quanto à inclusão ou exclusão social e econômica.

A partir das perspectivas dos autores supramencionados, tal modalidade de ensino é favorecida pelo uso das tecnologias, constituindo algo fundamental nos dias atuais, pois diminui as distâncias, contribui com a interação entre professores e alunos e vem acompanhar as transformações que ocorrem constantemente, porém requer o aprimoramento tecnológico das pessoas sob pena de não se adequarem a essa ferramenta que possibilita a aprendizagem na organização.

\section{PROCEDIMENTOS METODOLÓGICOS}

$\mathrm{Na}$ busca por compreender a realidade, em se tratando da abordagem do problema. A pesquisa teve um enfoque quanti-qualitativo. Quanto a ser uma análise predominantemente quantitativa, Kauark, Manhães e Medeiros (2010) revelam que pode ser expresso em números, opiniões e informações o que é quantificável, para classificá-las e analisá-las, o que requer o uso de recursos e de técnicas estatísticas (percentagem, média, moda, mediana, desviopadrão, coeficiente de correlação, análise de regressão), ferramentas que foram utilizados no presente estudo. $O$ estudo também é qualitativo por buscar um entendimento mais arraigado do fenômeno estudado, Silveira e Córdova (2009) mostram que o foco de atenção de tal pesquisa está voltado ao esclarecimento da dinâmica das relações sociais, assim como nos aspectos reais, o que não pode ser quantificado. Para Freitas e Jabbour (2011) essa combinação metodológica é considerada como algo robusto na produção do conhecimento, por ir além dos limites de cada uma delas (quantitativa e qualitativa).

Quanto aos meios, a investigação é de campo por ter sido realizado um contato mais aproximado com os sujeitos pesquisados, ao procurar informações diretamente com eles (GONSALVES, 2001).

A pesquisa quanto aos fins é exploratória, pela necessidade que se teve de se conhecer mais sobre o assunto, com a finalidade de uma maior familiaridade com o tema, através do esclarecimento e desenvolvimento de ideias (GIL, 2010). O estudo é descritivo pela observação, registros, análises, classificações e interpretações sobre o evento da EaD na Universidade Federal da Paraíba, segundo Andrade (2010) essas são práticas de tal estudo, sem a interferência do pesquisador.

Para Cruz Neto (2004, p. 51), "o trabalho de campo se apresenta como uma possibilidade de conseguirmos não só uma aproximação com aquilo que desejamos conhecer e estudar, mas também criar um conhecimento, partindo da realidade presente no campo." Desta forma, o universo da pesquisa é formado pelos servidores técnico-administrativos da Universidade Federal da Paraíba, que realizaram pelo menos um dos cursos oferecidos pela instituição, na modalidade à distância, os quais são: Conscientização em Segurança da Informação, Formação de Instrutores, Iniciação ao Serviço Público e Qualidade no atendimento ao cliente, ou seja, um conjunto pessoas constituídas de características equivalentes (VERGARA, 2014).

Para alcançar a finalidade da pesquisa, optou-se por uma determinada quantidade de elementos de uma classe (ANDRADE, 2010). Desta forma, a população amostral do estudo é

Perspectivas em Gestão \& Conhecimento, João Pessoa, v. 8, n. 1, p. 191-209, jan./abr. 2018. 
composta pelos servidores técnico-administrativos da UFPB, que chegaram a concluir um ou mais cursos na modalidade a distância no ano de 2016. A análise foi limitada a uma turma de cada curso, tendo em vista que durante o período de estudo, o curso de Conscientização em Segurança da Informação foi dividido em 2 turmas com 114 vagas, das quais chegaram a concluir 70 servidores, o de Iniciação ao Serviço Público foi ofertado em 4 turmas com 111 vagas e destas 96 concluíram, o de Qualidade no atendimento ao cliente em apenas uma turma com 13 vagas, apresentando destas 7 conclusões, enquanto que o de Formação de Instrutores não foi oferecido, ou seja, das 238 vagas ofertadas, apenas 173 servidores chegaram a concluir os cursos. Assim sendo, a amostra seria composta de 66 servidores, levando em consideração que a análise foi limitada a uma turma de cada curso, porém por ter sido inviável o contato com alguns e por outros estarem de licença, a amostra foi reduzida para 53 servidores, que representa um percentual de 31\% do total dos que concluíram, constituindo um percentual factível para a instituição investigada, para a generalização, recomenda-se outros estudos com um maior espaço amostral.

Os dados foram coletados por meio da aplicação de um questionário semiestruturado desenvolvido por Araújo (2017), porém para fins deste estudo foram utilizadas apenas as sete indagações fechadas e uma aberta, estabelecidas com base no nível Aprendizagem, pertencente ao modelo de avaliação de programas de treinamentos de Kirpatrick (2010a), o qual busca contribuir com o desempenho nas organizações ao avaliar a eficácia de tais programas, usando quatro níveis de avaliação: Reação, Aprendizagem, Comportamento e Resultados, sendo o questionário uma ferramenta que possibilitou adquirir diversas informações (KIRKPATRICK; KIRKPATRICK, 2010a). Assim sendo, esse modelo foi adaptado e usado para analisar como os cursos EaD contribuem com o processo de aprendizagem na organização, na percepção dos servidores técnico-administrativos da UFPB.

Ao ser aplicado o questionário, não teve a necessidade do respondente se identificar, pois o anonimato contribui com respostas mais concretas, por possibilitar mais segurança (FACHIN, 2006). As questões fechadas foram realizadas com as seguintes possibilidades de respostas: excelente, muito bom, bom, médio e ruim, as quais de acordo com Martins e Lintz (2013), procuram explicar algum atributo, remetendo a uma variação da escala de Likert, que compreende um grupo de itens propostos tendo a forma de afirmações e juízos, em que se pede ao sujeito que deixem claras as suas reações escolhendo as alternativas da escala.

Para melhor compreensão, os dados das questões fechadas foram agrupados de acordo com a Tabela 1, referente ao nível aprendizagem, baseado no modelo supramencionado.

Tabela 1- Indicadores dos cursos EaD

\begin{tabular}{|c|c|c|}
\hline Níveis & Questões & Descrição das questões \\
\hline \multirow{6}{*}{$\begin{array}{l}\mathbf{E} \\
\mathbb{d} \\
\frac{0}{0} \\
\frac{N}{0} \\
\frac{1}{0} \\
\frac{c}{d} \\
\frac{0}{0}\end{array}$} & Q1 & $\begin{array}{l}\text { Como você considera a sua preparação para começar os cursos de EaD quanto ao domínio } \\
\text { tecnológico? }\end{array}$ \\
\hline & Q2 & $\begin{array}{l}\text { Como você julga as informações sobre a realização dos cursos online fornecidas pela } \\
\text { organização? }\end{array}$ \\
\hline & Q3 & $\begin{array}{l}\text { Como você percebe o aumento dos seus conhecimentos na relevância no trabalho como } \\
\text { resultado dos cursos }\end{array}$ \\
\hline & Q4 & $\begin{array}{l}\text { Como você avalia o nível de interação e comunicação entre professores, tutores e alunos } \\
\text { no processo de geração de conhecimento? }\end{array}$ \\
\hline & Q5 & $\begin{array}{l}\text { Qual a sua percepção quanto o aprimoramento das suas habilidades ao desenvolver as } \\
\text { suas atividades diárias, a partir da conclusão dos cursos }\end{array}$ \\
\hline & Q6 & Como você considera as mudanças nas suas atitudes no ambiente de trabalho, diante da \\
\hline
\end{tabular}

Perspectivas em Gestão \& Conhecimento, João Pessoa, v. 8, n. 1, p. 191-209, jan./abr. 2018. 


\section{participação nos cursos on line?}

Técnicas estatísticas foram utilizadas para a análise e interpretação dos dados, as quais foram usadas para calcular, quando preciso, medidas de posição, tais quais: média, mediana, moda e medidas de dispersão como variância, desvio-padrão, coeficiente de variação (MARTINS, 2013).

Levando em consideração a relação de ordem que as categorias em escala Likert possuem, determinamos uma pontuação para cada opção, aqui definida como Escore Bruto, no qual atribuiu-se valor 1 à categoria "Ruim", 2 para "Médio", 3 para "Bom", 4 para "Muito Bom" e 5 para "Excelente". Para melhor avaliar os níveis separadamente, calculou-se um escore transformado, que varia dentro do intervalo [0;100]. Para tanto, utilizou-se a equação a seguir:

$$
E=[5 \bar{x}-5] \frac{100}{25^{x}}
$$

Onde $\bar{x}=\frac{1}{n} \sum_{i=1}^{n} x_{i}$ que corresponde à média dos Escores Brutos para cada respondente $\mathrm{e}$ $n$ equivale ao número de questões que compõem o nível aprendizagem.

A ferramenta Software $R$ foi utilizada, a qual é uma linguagem e um ambiente para computação estatística, em que é possível gerar gráficos, realizar testes, construir tabelas, etc. (R DEVELOPMENT CORE TEAM, 2011).

O teste de normalidade Shapiro-Wilk foi utilizado para avaliar se os escores transformados seguem distribuição normal (SHAPIRO e WILK, 1965). Definindo a hipótese nula (H0) como "os dados seguem distribuição normal" e a alternativa (H1) como sendo "os dados não seguem distribuição normal", o teste consiste em avaliar se rejeitamos ou não a hipótese nula. O resultado se dá pelo cálculo de um p-valor (probabilidade de rejeição da hipótese nula) associado à uma estatística de teste oriunda da comparação das informações do banco de dados com uma norma padrão através de fórmulas. É necessário também que se defina um nível de significância estatístico, que comumente utiliza-se $1 \%, 5 \%$ ou $10 \%$, correspondente à $0,01,0,05$ e 0,10, respectivamente. Caso o p-valor seja menor que o nível de significância adotado, rejeita-se a hipótese nula de que os dados seguem distribuição normal. Quando o oposto ocorre, tem-se evidências de que os dados seguem distribuição normal.

Para tratar a questão aberta: "Quais os fatores no ambiente de trabalho aparentam favorecer ou prejudicar a prática do que foi aprendido nos cursos?" , foi utilizada a análise de conteúdo, de forma a proporcionar clareza e enriquecimento da leitura, por ser um conjunto de técnicas de análise de comunicações (MOZZATO; GRZYBOVSKI, 2011), que de acordo com Bardin (2010) utiliza-se de procedimentos sistemáticos e objetivos que descrevem o que tem nas mensagens, mas isso não é suficiente, é preciso que após ser tratado a análise do material textual, possa extrair os saberes nele contidos.

Bardin (2011) apresenta três pólos cronológicos, que organizam as diferentes fases da análise de conteúdo, tais quais: (1) a pré-análise, (2) a exploração do material e o (3) tratamento dos resultados, a inferência e a interpretação. A análise do conteúdo no presente estudo foi orientada pelos polos supracitados. Na pré-análise foi o período da organização dos documentos, apresentando uma leitura flutuante dos mesmos e o estabelecimento de regras para análise, $\mathrm{Na}$ fase da análise do material, foi realizada a codificação e foram estabelecidas as categorias de análises dos dados coletados. Por fim, essa categorização possibilitou o tratamento dos resultados, inferência e interpretação. 


\section{APRESENTAÇÃO DOS RESULTADOS E DISCUSSÕES}

Conforme expresso nos procedimentos metodológicos, as questões fechadas do questionário foram analisadas e agrupadas através de percentuais e disponibilizadas por meio de gráficos e tabelas para um melhor entendimento dos dados. Já para a questão aberta, foi empregada a técnica de categorização, que pertence à análise de conteúdo utilizada por Bardin (2011). No primeiro momento, na pré-análise, as ideia iniciais obtidas, a partir das diversas leituras do material levantado, foram sistematizadas para que pudessem ser operacionais, possibilitando decisões precisas. Na fase a seguir de exploração do material, foram escolhidas as categorias de análises, que surgiram no momento da investigação, a partir dos resultados, assim como de um aporte a literatura que trata sobre o tema, em que foram investigadas as similaridades dos elementos, possibilitando o agrupamento destes de modo efetivo, os quais foram isolados e posteriormente divididos, facilitando a organização das mensagens e por fim, foram atribuídos significados aos resultados brutos, na fase do tratamento dos resultados e interpretação (ARAÚJO, 2017).

De acordo com Kirkpatrick e Kirkpatrick (2010a), no nível aprendizagem a avaliação se dá por meio das mudanças de comportamento, as quais estão expressas nas mudanças de atitudes, da evolução do conhecimento e das habilidades aprimoradas.

É possível visualizar na tabela 2 a seguir, que a maior quantidade de servidores, em média optou pela resposta "Muito Bom", às 7 perguntas fechadas que compõem o nível aprendizagem, as quais se referem a: domínio tecnológico, informações sobre a realização dos cursos, aumento do conhecimento, nível de interação e comunicação entre os personagens da EaD, aprimoramento das habilidades, mudanças de atitudes e evolução da aprendizagem em detrimento da participação dos cursos.

Observa-se que é necessário uma maior atenção com as informações a respeito da realização dos cursos, já que uma parcela considerável de $15,09 \%$ escolheu a resposta "Médio" para a Q2. De modo que, os colaboradores estejam cientes das oportunidades de cursos oferecidas, pois revelam interesse em continuarem se aperfeiçoando.

A maioria dos servidores escolheu na Q3 a opção "Muito Bom" em se tratando do aumento de conhecimento, em detrimento da participação nos cursos. O que mostra que a organização deve gerir o saber dos seus colaboradores. Os autores Alavi e Leidner (2001) ao pontuarem a respeito da GC dizem que os ativos do conhecimento geram competitividade sustentável para as empresas, uma vez que, não são fácies de serem copiados e são sociavelmente complexos, necessitando ser manipulados, armazenados e distribuídos para a geração de novos saberes, ou seja, que sejam aplicados eficazmente.

Em se tratando da Q4 mesmo que os seus percentuais dominantes variem entre "Bom" e "Muito Bom", há ainda um número de respostas para as opções "Ruim" e "Médio", no que se refere a interação e comunicação entre professores, tutores e alunos no processo de geração de conhecimento, o que remete a práticas que podem ser aperfeiçoadas pela instituição, as quais não devem ser negligenciadas nesse processo da EaD. Silva, Melo e Muyder (2015) destacam que a comunicação é primordial não apenas na interação entre professor/tutor/aluno, pois a institucionalização dos ambientes virtuais de aprendizagem necessita envolver todos os processos organizacionais. Em todas as etapas, mesmo que divergentes, a comunicação tem papel influenciador.

$\mathrm{Na}$ Q5 os servidores revelam que aprimoraram as suas habilidades ao desenvolver as suas atividades diárias, a partir da conclusão dos cursos. Na Q6 um percentual significativo de respostas "Muito Bom" 49,06\%, quanto ao aperfeiçoamento das atitudes, apesar de existir uma quantidade de resposta de 11,32\% para a opção "Médio", abrindo margem para o seu melhoramento. Na Q7 por apresentar um percentual de 49,05\% para a alternativa "Muito

Perspectivas em Gestão \& Conhecimento, João Pessoa, v. 8, n. 1, p. 191-209, jan./abr. 2018. 
Bom", observa-se que os colaboradores consideram ter evoluído na aprendizagem ao participarem dos cursos.

Coelho Jr. e Borges-Andrade (2008) enfatizam que investir no desenvolvimento de ações de aprendizagem eficazes na organização, de maneira tática e sintonizada com os seus objetivos, contribui de forma significativa com o desempenho organizacional.

Tabela 2 - Porcentagem das respostas por questão dos servidores técnico-administrativo da UFPB

\begin{tabular}{|c|c|c|c|c|c|c|c|c|c|c|c|}
\hline \multirow{2}{*}{ Nível } & \multirow{2}{*}{ Questões } & \multicolumn{2}{|c|}{ Ruim } & \multicolumn{2}{|c|}{ Médio } & \multicolumn{2}{|c|}{ Bom } & \multicolumn{2}{|c|}{ Muito Bom } & \multicolumn{2}{|c|}{ Excelente } \\
\hline & & $\mathbf{N}$ & $\%$ & $\mathbf{N}$ & $\%$ & $\mathbf{N}$ & $\%$ & $\mathbf{N}$ & $\%$ & $\mathbf{N}$ & $\%$ \\
\hline \multirow{7}{*}{ 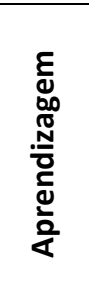 } & Q1 & - & - & 3 & 5,66 & 9 & 16,98 & 20 & 37,74 & 21 & 39,62 \\
\hline & Q2 & - & - & 8 & 15,09 & 20 & 37,74 & 18 & 33,96 & 7 & 13,21 \\
\hline & Q3 & - & - & 3 & 5,66 & 14 & 26,41 & 24 & 45,28 & 12 & 22,65 \\
\hline & Q4 & 2 & 3,77 & 4 & 7,55 & 19 & 35,85 & 18 & 33,96 & 10 & 18,87 \\
\hline & Q5 & 1 & 1,89 & 3 & 5,66 & 19 & 35,85 & 18 & 33,96 & 12 & 22,64 \\
\hline & Q6 & 1 & 1,89 & 6 & 11,32 & 12 & 22,64 & 26 & 49,06 & 8 & 15,09 \\
\hline & Q7 & - & - & 4 & 7,55 & 15 & 28,31 & 26 & 49,05 & 8 & 15,09 \\
\hline
\end{tabular}

Fonte: Araújo (2017)

Desta forma, vê-se pelo gráfico 1 que os percentuais para as categorias "Bom", "Muito Bom" e "Excelente" foram relativamente altos para grande maioria das perguntas.

Gráfico 1 - Nível Aprendizagem dos Servidores Técnico-administrativo da UFPB

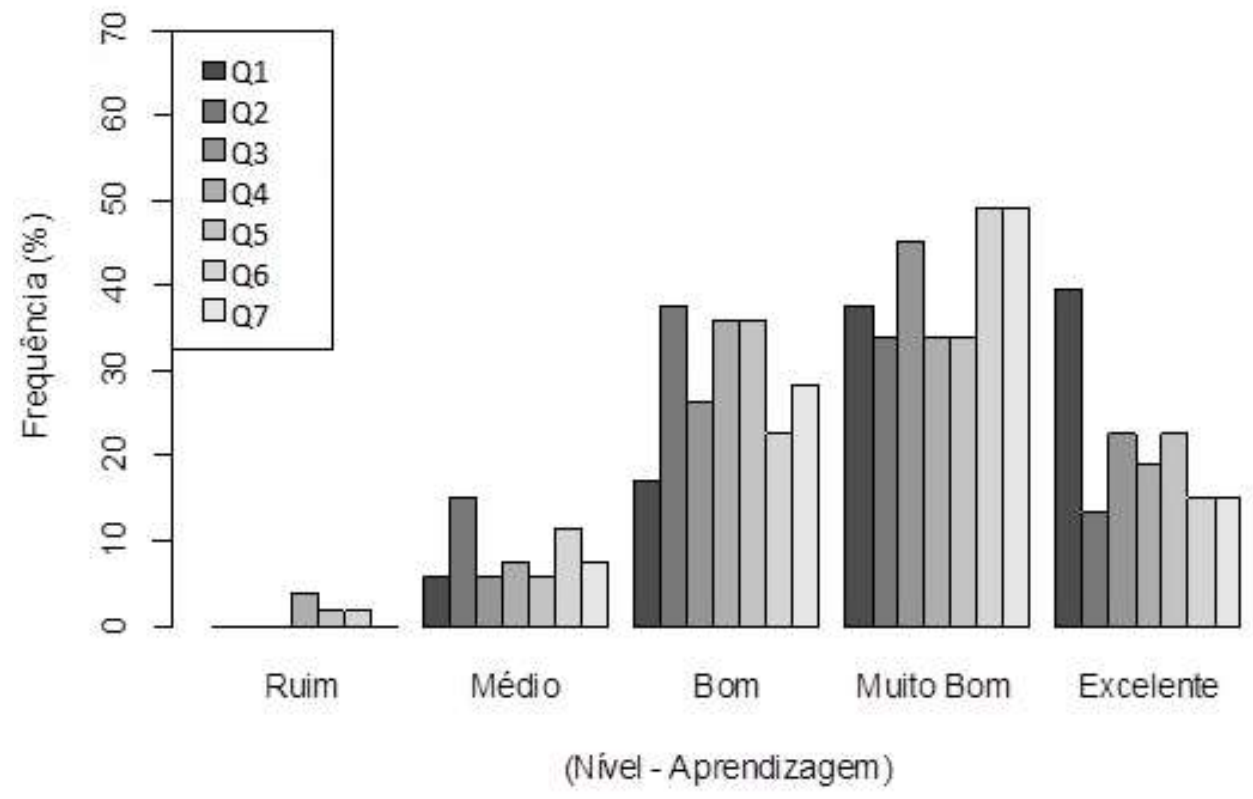

Fonte: Araújo (2017)

A média de Escores Brutos mais alta foi igual a 4,113, pertencente a Q1, que diz respeito a preparação dos pesquisados para começarem os cursos na modalidade $\mathrm{EaD}$, no que tange ao domínio tecnológico. Desta forma, eles consideram-se capacitados para tal. O que está expresso na tabela 3 a seguir:

Perspectivas em Gestão \& Conhecimento, João Pessoa, v. 8, n. 1, p. 191-209, jan./abr. 2018. 
Tabela 3 - Medidas descritivas dos Escores Brutos para cada questão

\begin{tabular}{|c|c|c|c|c|c|c|}
\hline \multirow{2}{*}{ Nível } & \multirow{2}{*}{ Questões } & \multicolumn{5}{|c|}{ Medidas Descritivas } \\
\hline & & Mínimo & Média & Mediana & Desvio Padrão & Máximo \\
\hline \multirow{7}{*}{ 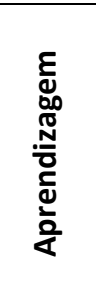 } & Q1 & 2 & 4,113 & 4 & 0,891 & 5 \\
\hline & Q2 & 2 & 3,453 & 3 & 0,911 & 5 \\
\hline & Q3 & 2 & 3,849 & 4 & 0,841 & 5 \\
\hline & Q4 & 1 & 3,566 & 4 & 1,009 & 5 \\
\hline & Q5 & 1 & 3,698 & 4 & 0,952 & 5 \\
\hline & Q6 & 1 & 3,642 & 4 & 0,942 & 5 \\
\hline & Q7 & 2 & 3,717 & 4 & 0,817 & 5 \\
\hline
\end{tabular}

Fonte: Araújo (2017)

O gráfico 2 de caixa a seguir ilustra a distribuição dos escores transformados, em que não existem escores discrepantes, o que revela a simetria dos resultados, o que é característica fundamental de uma distribuição normal de um determinado conjunto de informações.

Gráfico 2 - Distribuição dos Escores Transformados

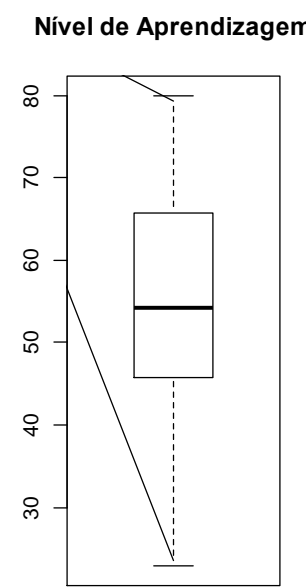

Fonte: Araújo (2017)

É possível visualizar pela Tabela 4, que as médias dos escores calculados é de 54,39 e que este valor se aproxima da respectiva mediana. Em razão dessa aproximação entre a média e a mediana suspeita-se de normalidade na distribuição dos dados, e ao aplicar o teste de normalidade Shapiro-Wilk obtemos p-valores maiores que um nível de significância de $1 \%$ $(0,01)$. Assim sendo, podemos concluir que os escores transformados podem ser descritos por uma distribuição normal. Com relação à medida de variabilidade, tem-se um desvio de 13,61, considerável para a precisão dos resultados. Apresentando ainda um escore no valor de 80,00, o que mostra que os servidores atribuíram alto conceito ao nível. 
Tabela 4 - Medidas descritivas e teste de Normalidade aplicado aos escores do nível aprendizagem

\begin{tabular}{cc} 
Medidas Descritivas & $\begin{array}{c}\text { Nível } \\
\text { Aprendizagem }\end{array}$ \\
\hline Mínimo & 22,86 \\
Média & 54,39 \\
Mediana & 54,28 \\
Desvio Padrão & 13,61 \\
Máximo & 80,00 \\
\hline Shapiro-Wilk (p-valor) & 0,4814 \\
\hline
\end{tabular}

Fonte: Araújo (2017)

Para incrementar as análises das questões fechadas, foi realizado um questionamento, para que os servidores se expressassem sobre os fatores no ambiente de trabalho que aparentam favorecer ou prejudicar a prática do que foi aprendido nos cursos, para tanto, foram levantadas seis categorias, a saber: local de trabalho, liderança, cultura organizacional, mudanças, interação e satisfação.

\subsection{Local de Trabalho}

A categoria local de trabalho foi a mais citada pelos servidores, para exemplificar das respostas obtidas:

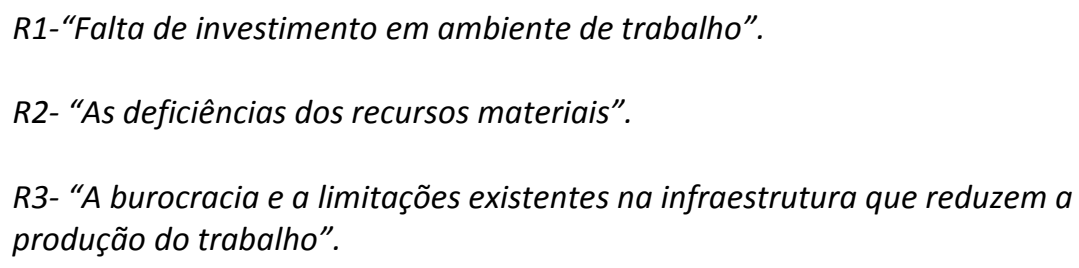

R1-"Falta de investimento em ambiente de trabalho".

R2- "As deficiências dos recursos materiais".

R3- "A burocracia e a limitações existentes na infraestrutura que reduzem a produção do trabalho".

Observa-se que os servidores apresentam como fator que pode prejudicar a prática do que foi aprendido nos cursos, as condições de trabalho inadequadas da organização, no tocante aos recursos materiais e a infraestrutura. Em que mostram a necessita da organização investir no seu ambiente laboral, de forma a proporcionar condições mais adequadas que favoreçam a produção do trabalho. Neste sentido, Segundo Rachel e Salomão (2011) um ambiente de trabalho favorável possibilita resultados positivos para a organização e a satisfação dos que a ela pertence.

\subsection{Liderança}

A categoria liderança assumiu a segunda posição das respostas obtidas, para ilustrá-la temos as seguintes afirmativas:

R1-"Incentivo pelas chefias aos seus colaboradores".

R2-"A falta de motivação dos chefes de departamento, tanto na liberação como nas barreiras impostas (complementação de horário) para a prática dos cursos".

Percebe-se que as atitudes da liderança, no que se refere ao incentivo para a realização dos cursos influenciam na execução do que foi aprendido. Constata-se que os servidores solicitam que ao invés da chefia impor barreiras, a exemplo dos horários, crie

Perspectivas em Gestão \& Conhecimento, João Pessoa, v. 8, n. 1, p. 191-209, jan./abr. 2018. 
oportunidades que os estimulem com a realização e a prática dos cursos. Diante desta perspectiva, Ribeiro (2012) trata do valor de visualizar as pessoas como parceiras e que cabe a área de recursos humanos empreender ações que desenvolvam os seus talentos. Rachel e Salomão (2011) ratificam a ideia ao destacarem a importância do incentivo de oportunidade de desenvolvimento profissional para os colaboradores.

\subsection{Cultura Organizacional}

A categoria cultura organizacional ficou em terceiro lugar, a qual está expressa nas seguintes falas dos servidores:

R1- "A presença de um processo tácito e ultrapassado enraizado na instituição".

R2-"Muitas vezes não é possivel aplicar o conhecimento pela falta de conscientização e práticas costumeiras".

Diante das respostas dos servidores, a organização possui uma cultura arraigada que impõe barreiras, impossibilitando a aplicação do conteúdo dos cursos, precisando desta forma ser revista e analisada, para aproveitar o conhecimento adquirido na realização dos cursos, dando abertura a implantação de novas ideias. Vieira e Francisco (2012) falam que o desafio da educação corporativa é criar uma cultura inovadora, em que a educação é um processo ligado a toda forma de trabalho, contemplando todos os níveis da organização.

\subsection{Mudanças}

A categoria Mudanças obteve o quarto lugar quanto a prejudicar ou favorecer a prática o que foi aprendido nos cursos EaD, em que os servidores disseram que a resistência a mudanças da equipe de trabalho é um fator prejudicial. $\mathrm{O}$ que pode ser constatado nos seus dizeres:

\section{R1-"Colegas de trabalho que possuem algumas resistências". \\ R2- "A relação de aceitação de mudanças entre colegas de trabalho". \\ R3-"A equipe está aberta a novos aprendizados".}

Observa-se que a resistência de adaptação as mudanças dos colegas de trabalho compromete o equilíbrio entre a teoria dos cursos e sua prática, o que pode ocorrer pelo fato de terem estabilidade, não considerarem ser necessário enfrentar novos desafios, porém a sociedade exige constantemente serviços de qualidade, necessitando assim, que os servidores estejam em contínua capacitação. Ao fazer uma comparação com a iniciativa privada, Albertin e Brauer (2012) revelam que é mais comum a aversão a mudanças no setor público, pela estabilidade, o que acaba restringindo o poder de negociação do gestor, Assim sendo, é necessário que este tenha a preparação adequada para lidar com essa situação, de forma a contribuir com a efetividade dos projetos organizacionais. 


\subsection{Interação}

As categorias interação e satisfação ficaram iguais, no quinto lugar. Neste contexto, começando pela análise da categoria interação, os colaboradores nas suas expressões consideraram a cooperação entre os colegas de trabalho um fator que pode favorecer a prática do que foi assimilado, uma vez que, disseram:

R1-"A cooperação aparenta favorecer o que foi aprendido nos cursos".

R2- "A interação entre todos os servidores do setor coopera para o desenvolvimento positivo do trabalho".

Observa-se que a aprendizagem organizacional evolui, quando os servidores desenvolvem o seu trabalho com alinhamento, o que reverbera em ações contributivas. $O$ que torna fundamental que a UFPB estimule que os seus servidores trabalhem na mesma direção, de forma que com isso venha ser beneficiada com um clima organizacional favorável e que tenha proveito do que foi ministrado do conteúdo dos cursos. Os atores Brandão e BorgesAndrade (2007) dizem existir evidências práticas, que dentre outros fatores, o suporte disponibilizado aos colaboradores pelos colegas cooperam a transferência de aprendizagem, ou seja, a manifestação de competências no trabalho. No que tange ao clima organizacional, Ferreira (2017) alerta para a necessidade de que ele seja identificado e analisado constantemente, por estar atrelado a motivação do colaborador, contribuindo consequentemente com a produtividade organizacional.

\subsection{Satisfação}

A categoria satisfação é representa pelos seguintes dizeres dos servidores:

R1-"O ambiente de trabalho oferece o aparato para colocar em prática o que foi aprendido"

R2- "O conhecimento adquirido é totalmente aplicado no cotidiano".

Uma quantidade menos expressiva de servidores consideraram a organização como cenário que possui as condições ideais para a prática do que foi aprendido, pois se mostraram satisfeitos. Os autores Coelho Jr. e Borges-Andrade (2008) destacam que um cenário apropriado e a motivação daquele que está aprendendo constituem aspectos essenciais para o sucesso ou fracasso de uma ação de aprendizagem.

\section{CONSIDERAÇÕES FINAIS}

Por meio do estudo realizado baseado no nível aprendizagem, foi possível atender o objetivo geral da pesquisa sobre analisar de que forma os cursos na modalidade a distância contribuem com a aprendizagem na organização, a partir da percepção dos servidores técnicoadministrativos da UFPB, assim como, os objetivos específicos de verificar a partir da visão destes colaboradores a utilidade dos cursos EaD, na realização dos seus trabalhos e o de identificar as barreiras que podem prejudicar o emprego eficiente do que foi aprendido a partir dos cursos na modalidade a distância, na percepção dos entrevistados, uma vez que, por meio dele foi possível constatar a utilidade desses cursos, pois é notório que os servidores tenham aprimorado as suas competências, a partir do aumento do conhecimento, da evolução 
da habilidades e assim como das atitudes, levando para a prática o que foi adquiro, num processo que favorece a aprendizagem no âmbito organizacional

Os servidores também demonstraram respostas positivas quanto a preparação domínio tecnológico. Em relação as informações sobre os cursos e a interação entre os personagens da EaD, alertaram pra um melhoramento, apesar da predominância das respostas favoráveis.

Diante das respostas obtidas foi constatado através do teste Shapiro- Wilk, que os escores que foram utilizados podem ser descritos por uma distribuição normal, ou seja, existe normalidade na distribuição dos dados.

De modo geral foram expressos alguns fatores que podem favorecer ou prejudicar a utilidade desses cursos $\mathrm{EaD}$, como a falta de investimento em materiais e infraestrutura no ambiente de trabalho, a ausência da chefia no estímulo a participação em tais cursos, uma cultura organizacional fechada a prática de boas ideias, a resistência dos colegas de trabalho as mudanças e a interação entre eles mesmos.

Mediante essa realidade, sugere-se que a organização busque gerenciar o conhecimento das pessoas, aproveitando da melhor forma, já que houve um avanço a partir dos cursos; a liderança deve estar mais presente se mostrando interessada ao incentivar os colaboradores a participarem dos cursos, sendo flexíveis quantos aos horários e com uma maior divulgação para que seja despertado o interesse na realização, recomenda-se que a organização reveja a sua cultura e leve em consideração a importância dela ser inovadora, que esteja apta à educação dos colaboradores, assim como da aplicabilidade do que foi aprendido, ou seja, aberta a novas ideias. O estímulo aos colaboradores da adaptação a mudanças, assim como a promoção da interação entre eles é aconselhável para um melhor aproveitamento dos cursos.

Indicamos como possibilidade de estudos futuros o desenvolvimento de pesquisas que possibilitem desvendar os impactos associados com os processos de gestão do conhecimento que foram adquiridos por meio dos cursos EaD e sobre a importância desta no papel da liderança e incentivo na qualificação dos servidores.

\section{REFERÊNCIAS}

ALAVI, M.; LEIDNER, D. E. Review: knowledge management and knowledge management systems: conceptual foundations and research issues. MIS Quarterly. Minnesota, v. 25, n. 1. Mar. 2001, pp.107-136. Disponível em: https://moodle.ufsc.br/pluginfile.php/950622/mod resource/content/1/MISQ\%202001\%20Vo \%2025\%20No.\%201\%20page\%20107\%20Alavi\%20Leidner.pdf>. Acesso em: 09 out. 2016.

ALBERTIN, A. L.; BRAUER, M. Resistência à educação à distância na educação corporativa. Revista de Administração Pública. Rio de Janeiro, v. 46 n.5. Sept./Oct. 2012.

Disponível em: $\quad$ http://www.scielo.br/scielo.php?script=sci arttext\&pid=S003476122012000500009\&lng=en\&tlng=en. Acesso em: 24 out. 2016.

ANDRADE, M. M. Introdução à metodologia do trabalho científico. 10. Ed. São Paulo, Ed. Atlas, 2010.

ARAÚJO, D. G. Contribuições de educação corporativa na modalidade a distância: um estudo na Universidade Federal da Paraíba. João Pessoa, 2017. 133 f. Dissertação (Mestrado em Gestão nas Organizações Aprendentes) - Universidade Federal da Paraíba, João Pessoa, 2017.

BARDIN, L. Análise de conteúdo. 5. ed. Lisboa: Edições 70, 2010. 
. Análise de conteúdo. 6. ed. Lisboa: Edições 70, 2011.

BEHAR, P. A. et al. Educação à distância e competências. In: BEHAR, P.A. (Org.). Competências em educação à distância à distância. Porto Alegre: Penso, 2013. p.42-54.

BIACHI, E. M. P.G. Didática e educação corporativa: o desafio empresarial da educação continuada. Revistas Gerenciais, São Paulo, v.7, n.1, p.73-82, 2008. Disponível em: http://www.revistaiberoamericana.org/ojs/index.php/ibero/article/view/969/1285. Acesso em: 31 out. 2016.

BRANDÃO, H. P.; BORGES-ANDRADE, J. E. Causas e efeitos da expressão de competências no trabalho: para entender melhor a noção de competência. RAN - Revista de Administração Mackenzie, São Paulo, v. 8, n.3, p.32-49, 2007. Disponível em: http://editorarevistas.mackenzie.br/index.php/RAM/article/view/136/136. Acesso em: 06 out. 2016.

CHERMAN, A. Gestão do conhecimento. In: RAMAL, A.(Org.). Educação corporativa: como implementar projetos de aprendizagem nas organizações. Rio de Janeiro: LTC, 2012. p. 58-89.

COELHO JUNIOR, F. A.; BORGES-ANDRADE, J. E. Uso do conceito de aprendizagem em estudos relacionados ao trabalho e organizações. Paidéia, Ribeirão Preto, 18 (40), p.221-234, 2008. Disponível em: http://www.scielo.br/pdf/paideia/v18n40/02.pdf. Acesso em: 06 out. de 2016.

CRUZ NETO, O. O trabalho de campo como descoberta e criação. In: MINAYO, M. C.S (Org.). Pesquisa Social: teoria, método e criatividade. 23. ed. Petrópolis: Vozes, 2004.

EBOLI, M. Fundamentos, princípios e práticas da educação corporativa. In: EBOLI, M. (Org.). Educação corporativa: muitos olhares. São Paulo: Atlas, 2014. p.14-27.

FACHIN, O. Fundamentos de metodologia. 5 ed. São Paulo: Saraiva, 2006.

FERREIRA, P.I. Clima organizacional. In: RAMAL, A. (Org.). Clima organizacional e qualidade de vida no trabalho. Rio de Janeiro: LTC, 2017. p. 45-68.

- Gestão por competência. In: RAMAL, A.(Org.). Educação corporativa: como implementar projetos de aprendizagem nas organizações. Rio de Janeiro: LTC, 2012. p.34-57.

FREITAS, W. R.S.; JABBOUR, C. J. C. Utilizando estudo de caso(s) como estratégias de pesquisa qualitativa: boas práticas e sugestão. Estudo \& Debate, Lajeado, v. 18, n. 2, p.07-22, 2011.Disponível

em: http://univates.br/revistas/index.php/estudoedebate/article/viewFile/560/550. Acesso em: 02 dez. 2016.

GIL, A. C. Como elaborar projetos de pesquisa. 5. ed. São Paulo: Atlas, 2010.

Gestão de Pessoas: enfoque nos papéis profissionais. 1. ed. 12. Reimpressão. São Paulo: Atlas, 2012.

GONSALVES, E. P. Conversas sobre iniciação a pesquisa científica. Campinas: Alínea, 2001. 
HEEMANN, Christiane. A aprendizagem nas organizações: comunidades de prática e letramento digital. Texto Livre: Linguagem e Tecnologia, [S.1], v.6, n.2, p. 78-89, nov. 2013. Disponível em: http://www.periodicos.letras.ufmg.br/index.php/textolivre/article/view/5083/7227. Acesso em: 09 jan. 2018.

HOURNEAUX JUNIOR, F.; DIAS, C. F. Investimentos e resultados em educação corporativa. In: EBOLI, M. (Org.). Educação corporativa: muitos olhares. São Paulo: Atlas, 2014. p.101-109.

IANNI, O. Teorias da Globalização. 9 ed. Rio de Janeiro: Civilização Brasileira, 2001.

KAUARK, F.; MANHÃES, F. C.; MEDEIROS, C. H. Metodologia da pesquisa: guia prático. Itabuna: Via Litterarum, 2010.

KIRKPATRICK, D. L; KIRKPATRICK, J. D. Como avaliar programas de treinamentos de equipes: os quatro níveis. Tradução de: José Lamensdorf. Revisão técnica: Klalter Fontana. Rio de Janeiro: Senac Rio. 2010a.

. Como implementar os quatro níveis de avaliação de treinamento de equipe: um guia prático. Tradução de: Alessandra Mussi. Rio de Janeiro: Senac Rio, 2010b.

KURTZ, R. Gestão de aprendizagem on-line na educação corporativa. In: RAMAL, A.(Org.). Educação corporativa: como implementar projetos de aprendizagem nas organizações. Rio de Janeiro: LTC, 2012. p.202-231.

MACHADO, D. P.; MORAES, M. G. S. Educação à distância: fundamentos, tecnologias, estrutura e processos de ensino e aprendizagem. São Paulo: Érica, 2015.

MACHADO, L. R.; LONGHI, M. T.; BEHAR, P. A. In: BEHAR, P. A. (Org.). Competências em educação à distância. Porto Alegre: Penso, 2013. p.56-80.

MARTINS, G. A. Manual para elaboração de monografias e dissertações. 3. ed.São Paulo: Atlas, 2013.

. LINTZ, A. Guia para elaboração de monografias e trabalhos de conclusão de curso. 2 ed. São Paulo: Atlas, 2013.

MÓSCA, H. M. B. Gestão de pessoas na organização contemporânea. In: RAMAL, A.(Org.). Educação corporativa: como implementar projetos de aprendizagem nas organizações. Rio de Janeiro: LTC, 2012. p. 3-33.

MOZZATO, A. R.; GRZYBOVSKI, D. Análise de conteúdo como técnica de análise de dados qualitativos no campo da administração: potencial e desafios. RAC, Curitiba, v. 15, n. 4, p.731747, Jul./Ago. 2011. Disponível em: http://www.scielo.br/pdf/rac/v15n4/a10v15n4.pdf. Acesso em: 05 dez. 2016.

NEIVA, E. R.; RAMOS, L. D. Contexto de mudança organizacional: sua influência sobre a aprendizagem, as redes sociais e as competências aprendidas no trabalho. In: ENCONTRO ANUAL DA ASSOCIAÇÃO DOS PROGRAMAS DE PÓS-GRADUAÇÃO EM ADMINISTRAÇÃO ENANPAD, 2013, 37., Rio de Janeiro. Anais... Rio de Janeiro: Anpad, 2013. Disponível em: 
http://www.anpad.org.br/admin/pdf/2013 EnANPAD EOR1970.pdf. Acesso em: 06 out. 2016.

OLIVEIRA, P.C.; CUNHA, C. J. C. A.; NAKAYAMA, M. K. Learning Management Systems (LMS) and E-Learning Management: An Integrative Review and Research. Journal of Information Systems and Technology Management, v. 13, n. 2, p.157-180, 2016.

PALMEIRA, C. Avaliação de resultados em educação corporativa. In: RAMAL, A.(Org.). Educação corporativa: como implementar projetos de aprendizagem nas organizações. Rio de Janeiro: LTC, 2012. p.232-260.

RACHEL, L. A.; SALOMÃO, A. H. M. Cultura e clima organizacional como estratégias de impacto no desempenho. 2011. Disponível em: http://machadosobrinho.com.br/revista online/publicacao/artigos/Artigo04REMS4.pdf. Acesso em: 07 out. 2016.

$R$ DEVELOPMENT CORE TEAM.A language and environment for statistical computing. $R$ Foundation for StatisticalComputing, Vienna, Austria, 2011. Disponível em: http://www.Rproject.org/. Acesso em: 2 junho de 2017.

RIBEIRO, A. L. Gestão de pessoas. 2 ed. São Paulo: Saraiva, 2012.

RODRÍGUEZ, J. O modelo de Kirkpatrick para a avaliação da formação. 2005. Disponível em: http://www.uhu.es/yolanda.pelayo/docencia/Virtualizacion/2contenidos/parte\%204/MODELO\%20DE\%20KIRCKPATRICK.pdf Acesso em 17 jan. 2018.

ROSSINI, A. M. As novas tecnologias da informação e a educação à distância. 2. ed. São Paulo: Cengage Learning, 2013.

SCHIKMANN, R. Gestão Estratégica de Pessoas: bases para a concepção do Curso de Especialização em Gestão de Pessoas no Serviço Público. In: CAMÕES, M. R. S.; PANTOJA, M. J.; BERGUE, S. T. Gestão de pessoas: bases teóricas e experiências no setor público/org. Brasília: ENAP, 2010.

SENGE, P. M. A quinta disciplina: arte e prática da organização que aprende. Tradução de: Gabriel Zide Neto. 31a ed. Rio de Janeiro: BestSeller, 2016.

SHAPIRO, S. S.; WILK, M. B. An analysis of variance test for normality (complete samples). Biometrika. 52 (3-4): 591-611. doi: 10.1093/biomet/52.3-4.591. JSTOR 2333709. MR 205384. p. 593, 1965.

SILVA, M. P. D.; MELO, M. C. O. L.; MUYLER, C. F. Educação à distância em foco: um estudo sobre a produção científica brasileira. RAM, Rev. Adm. Mackenzie. vol.16 no.4, p.202-230.São Paulo July/Aug. $2015 . \quad$ Disponível em: http://www.scielo.br/scielo.php?script=sci arttext\&pid=S1678-69712015000400202. Acesso em: 26 nov. 2016.

SILVA, N. P. et al. Avaliando as práticas de educação corporativa à distância por meio do modelo de Kirkpatrick: um estudo de caso numa empresa do ramo de energia no estado do Paraná. Emancipação, Ponta Grossa, v.10, n.2, p.501-515, 2010. Disponível em: 
http://www.revistas2.uepg.br/index.php/emancipacao/article/viewFile/815/1884.Acesso em: 16 nov. 2016.

SILVEIRA, D. T.; CÓRDOVA, F. P. A pesquisa científica. In: GERHARDT. T. E.; SILVEIRA, D.T. (Orgs). Métodos de Pesquisa. Porto Alegre: Editora da UFRGS, 2009.

TEIXEIRA, G.; STEFANO, S. R.; CAMPOS, E. A. R. E-learning, percepções sobre satisfação no treinamento à distância em instituições financeira: reação versus impacto. Race: revista de administração, contabilidade e economia.V. 14, n. 1, p.225-250, jan.abr. 2015. Disponível em: http://editora.unoesc.edu.br/index.php/race/article/view/4735/3727. Acesso em: 30 nov. 2016.

VERGARA, S. C. Projetos e relatórios de pesquisa em administração. 15 ed. São Paulo: Atlas, 2014.

VIEIRA, F. H. A.; FRANCISCO, A. C. Etapas da implementação da educação corporativa e seus impactos em empresas brasileiras: um estudo multicaso. São Paulo, vol. 22, n. 2, p.296-308, 01 de Abr. 2012. Disponível em: http://www.scielo.br/scielo.php?script=sci arttext\&pid=S0103-65132012000200010. Acesso em: 24 out. 2016.

ZAVATTI, W. Y. Y.; BALDUÍNO M. A. C. Educação corporativa no setor público: um estudo sobre o tribunal de contas do estado de Goiás. Goiânia, 2013. Disponível em: http://www.academia.edu/6467494/EDUCA\%C3\%87\%C3\%830 CORPORATIVA NO SETOR P \%C3\%9ABLICO UM ESTUDO SOBRE O TRIBUNAL DE CONTAS DO ESTADO DE GOI\%C3\%8 1S 1. Acesso em: 06 out. 2016.

Artigo recebido em 10/10/2017 e aceito para publicação em 19/03/2018 